\title{
Possibilidades de consumo dos espaços de aparição, partilhas de gênero e performatividades
}

Possible Ways to Consume Spaces of Appearance, Gender-Based Shares and Performances

Possibilités de consommation des espaces d'apparition, partages de genre et performativités

Eliza Bachega Casadei e Andrey Albuquerque Mendonça

\section{(2) OpenEdition}

\section{Journals}

Edição electrónica

URL: https://journals.openedition.org/rccs/12455

DOI: $10.4000 /$ rccs. 12455

ISSN: 2182-7435

\section{Editora}

Centro de Estudos Sociais da Universidade de Coimbra

\section{Edição impressa}

Data de publição: 1 dezembro 2021

Paginação: 113-132

ISSN: 0254-1106

\section{Refêrencia eletrónica}

Eliza Bachega Casadei e Andrey Albuquerque Mendonça, «Possibilidades de consumo dos espaços de aparição, partilhas de gênero e performatividades», Revista Crítica de Ciências Sociais [Online], 126 | 2021, publicado a 27 janeiro 2022, consultado a 29 janeiro 2022. URL: http://journals.openedition.org/ rccs/12455 ; DOI: https://doi.org/10.4000/rccs.12455 


\title{
ELIZA BACHEGA CASADEI, ANDREY ALBUQUERQUE MENDONÇA
}

\section{Possibilidades de consumo dos espaços de aparição, partilhas de gênero e performatividades}

\begin{abstract}
A partir de uma reflexão sobre a constituição do espaço como um campo das lutas por reconhecimento, o objetivo do presente artigo é estudar as possibilidades diferenciais do consumo de espaços de aparição para homens e mulheres na Igreja Hillsong. Analisaremos como os seus valores religiosos em relação aos gêneros se materializam menos no conteúdo da enunciação do que na performatividade da constituição dos espaços em que o gênero pode ser enunciado. Recorrendo à Análise Crítica do Discurso, estudaremos a representação dos espaços nas imagens publicadas em 2019 no perfil do Instagram da Hillsong São Paulo a partir de um recorte de gênero. Os espaços diferenciais de aparição nesta Igreja são não apenas um modo de organização dos corpos em assembleia, mas um conjunto vivo de relações, que performativamente instrumentaliza os modos de aparição autorizados e podem ser interpretados como espaços morais de aparição de gênero.
\end{abstract}

Palavras-chave: desigualdade de género; instituições religiosas; práticas religiosas; representação de género.

\section{Introdução}

A pergunta que estrutura a presente pesquisa se situa na confluência de uma contradição: embora muitas instituições sociais, no plano do conteúdo de suas afirmações, advoguem a favor da igualdade de gênero, ainda assim, em suas práticas, é possível observar posições conservadoras e retrógradas em suas lógicas de representação. Como um recorte dessa contradição, podemos observar instituições religiosas em que as possibilidades de consumo dos espaços de aparição são diferentes para homens e para mulheres, muito embora essa diferença não apareça no plano do conteúdo, mas sim nos discursos e práticas que estruturam tais espaços.

Para que possamos abordar a questão de como os valores de gênero são comunicados, mediados e reproduzidos (não apenas a partir do discurso verbal, mas a partir da distribuição de espaços de visibilidade nas práticas religiosas), escolhemos como estudo de caso os dispositivos comunicacionais 
da Igreja Hillsong - uma igreja australiana fundada em 1983, pelo casal Brian e Bobbie Houston, que chegou à cidade de São Paulo em 2016. Uma das suas características marcantes é a sua presença significativa nas mídias digitais, de forma que sua principal plataforma de divulgação é a rede social Instagram (em 2019, o perfil da Igreja contava com 2,1 milhões de seguidores). A estratégia comunicacional voltada para fotografias em redes sociais implica, para a Hillsong, a construção de espaços de visibilidade que convocam os fiéis à produção e consumo de imagens de si mesmos, carregadas de partilhas de valores díspares diferenciais entre os gêneros.

O objetivo deste artigo é estudar as possibilidades diferenciais do consumo de espaços de aparição de homens e mulheres na Hillsong. Estudaremos, a partir das estratégias de comunicação da entidade, como os seus valores religiosos se distribuem de maneira diferencial entre os gêneros a partir da constituição de espaços de visibilidade. $\mathrm{Na}$ análise, é possível depreender que a distribuição diferencial de valores entre os gêneros se encontra não apenas no conteúdo da enunciação, mas na própria performatividade da constituição dos espaços (de acordo com Butler, 2019 [2015]) em que o gênero pode ser enunciado, ou seja, na materialidade das práticas comunicativas.

Metodologicamente, essa abordagem se alinha aos pressupostos de um eixo da Análise Crítica do Discurso (ACD) que investiga o controle do discurso e suas formas de produção, a partir da formulação de van Dijk de que "um elemento importante na reprodução discursiva do poder é o próprio acesso ao discurso e a eventos comunicativos" (2010: 89; itálico no original). Como corpus de pesquisa, investigaremos as produções (fotografias e vídeos) da página da Hillsong São Paulo no Instagram, ${ }^{1}$ publicadas ao longo do ano de 2019, com o objetivo de avaliar como são midiatizadas as relações espaciais de poder no interior da congregação.

Iremos discutir, em um primeiro momento, como a construção dos espaços de visibilidade implica em mediação de valores de gênero para além do conteúdo enunciado e explicaremos o que entendemos por possibilidades de consumo de espaços de aparição; na sequência, apresentaremos as estratégias comunicacionais da Hillsong e analisaremos como suas práticas implicam possibilidades diferenciais de aparecimento do corpo masculino e feminino no espaço comunicativo construído.

${ }_{1}^{1}$ Disponíveis em https://www.instagram.com/hillsongsaopaulo/?hl=pt-br. Última consulta a 20.05.2020. 


\section{As possibilidades de consumo dos espaços de aparição diferenciais entre os gêneros}

O primeiro ponto que precisa ser esclarecido é o conceito de "espaços de aparição" (spaces of appearance). Proposto por Butler (2019 [2015]), este conceito parte do princípio de que, para além dos discursos verbais que urdem as lutas políticas, há uma performatividade no estar junto que é importante para entendermos as articulações de poder que as estruturam. Assim, "reuniões silenciosas, incluindo vigílias e funerais, muitas vezes significam mais do que qualquer relato, escrito ou vocalizado, sobre aquilo que elas tratam" (ibidem: 14). Posto que o próprio poder que as pessoas têm de se reunir a partir de uma representação corpórea concentrada é em si um ato político, há, para a autora, uma "importante relação quiasmática entre as formas de performatividade linguística e as formas de performatividade corpórea" (ibidem). As agremiações e assembleias são não apenas espaços de reunião, mas principalmente, de comunicação, ao propagar uma instância de exposição de valores. A articulação de formas de corporalidade à constituição de espaços diferenciais de visibilidade e reconhecimento mostra, para Butler (2019: 46), que a "ação corporal concertada", - ou seja, "todas as partes da assembleia que não são rapidamente assimiladas pelo discurso verbal" - é um importante eixo para o entendimento sobre as lutas políticas contemporâneas, em especial as que dizem respeito às partilhas de valores de gênero. Isso é interessante na medida em que implica que as possibilidades de consumo dos espaços de aparição são entendidas como elementos que articulam os campos de reconhecimento, estabelecendo partilhas entre o que deve ser visibilizado ou não em termos de valores de gênero nas configurações de reunião.

Em outros termos, o espaço de aparição, para Butler (2019: 46), está vinculado a normas de reconhecimento hierárquicas e excludentes, pelo que "a performatividade de gênero está assim ligada às formas diferenciais por meio das quais sujeitos se tornam passíveis de reconhecimento". Essa asserção tem duas implicações principais para a autora: a de que "reconhecer um gênero muitas vezes envolve reconhecer uma determinada conformidade corporal com uma norma" (ou seja, um discurso); e a de que é necessário "reivindicar para si a esfera pública" em busca desse reconhecimento (ibidem).

É a partir dessa reivindicação do espaço público que podemos entender que as oportunidades de consumo de espaços de aparição não são homogêneas para todos os grupos sociais, de modo que certas formas de visibilidade são permitidas para uns e proibidas para outros. Trata-se de um importante elemento de reconhecimento das demandas de gênero, de maneira que 
o acesso e controle das formas de produção comunicativas medeiam e reproduzem valores acerca dos quais são legitimados estilos de vida. E isso porque "ser um sujeito requer primeiro encontrar o próprio caminho dentro de certas normas que governam o reconhecimento", de forma que "se não conseguimos encontrar nosso caminho dentro das normas de gênero ou sexualidade que nos foram designadas [...] ficamos expostos ao que significa estar nos limites da condição de reconhecimento" (Butler, 2019: 47), o que implica estar em lugar sujeito a violências e exclusões de diversas ordens.

O direito de aparecer é apoiado por esquemas regulatórios que qualificam sujeitos que são elegíveis ao mesmo, a partir de normas de reconhecimento, sendo que "não importa 'quão universal o direito de aparecer reivindique ser, o seu universalismo é minado por formas diferenciais de poder que qualificam quem pode e quem não pode aparecer" (ibidem: 57). Falar sobre as possibilidades comunicacionais de aparecimento dos gêneros implica falar sobre formas diferenciais de poder. As formas políticas do aparecimento, nas quais se incluem as lutas de gênero são, sobretudo, uma luta pelas formas de limitação e mediação das estratégias comunicacionais.

Uma das implicações é que "algumas vezes essa face pública pode ser um conjunto de palavras e, outras vezes, os corpos nas ruas não precisam falar para expor a sua reivindicação" (ibidem: 62). E isso porque a própria materialidade dos corpos reunidos em assembleia já articula suas formas de aparição: "se você aparece como um corpo na rua, você ajuda a fazer a reivindicação que surge desse conjunto plural de corpos, reunidos e persistindo ali" (ibidem: 65), exigindo o exercício de pertencer a um espaço de visibilidade. "Os corpos congregam, eles se movem e falam juntos", a partir do pleiteamento de um espaço como público (ibidem: 80).

Quando nos referimos às possibilidades de consumo de espaços de aparição, portanto, estamos nos referindo justamente aos arranjos diferenciais em que os grupos são autorizados e legitimados a exercer o direito de aparecer dentro de um campo de visibilidades regulado por uma determinada instituição social que, a partir de suas estratégias comunicativas, organiza um determinado espaço de aparição.

De entre as diversas formas de assembleia estruturadas por ações corpóreas de gênero, a religião ocupa um papel central. Como apontado por Machado (2005: 387), as opções religiosas são importantes no "processo de reconfiguração das subjetividades femininas e masculinas no interior das comunidades", uma vez que regulam elementos vinculados à sexualidade, aos ideais de família, ao etos privado e controle dos corpos. A religião se constitui como um dispositivo "de produção de discursos sobre o sexo [...] que extrapola os limites da espiritualidade [...] para se tornar [...] essencial 
aos mecanismos de poder, com a implantação do dispositivo da sexualidade" (Busin, 2011: 112). As assembleias religiosas constituem, assim, espaços tradicionais em que as lutas pelo consumo de espaços de aparição de gênero estão bastante marcadas.

Quando falamos de corpos reunidos em um espaço de visibilidades, um aspecto importante é que esse espaço não é dado a priori. Trata-se de um espaço que é, ele próprio, performativo. Isto significa que se trata de um espaço que é construído como espaço de visibilidade em sua própria enunciação. Os corpos reunidos reivindicam o espaço, "encontrando-o e produzindo-o por meio da apreensão e da reconfiguração dos ambientes materiais" (Butler, 2019: 81).

O pleiteamento do espaço é formado por objetos não humanos e estruturas materiais que sugerem um tipo particular de atuação dentro daquele espaço, um modo particular de concebê-lo e utilizá-lo. Assim, os corpos individualmente não estabelecem propriamente um espaço de aparição: as possibilidades de visibilidade estão na urdidura entre a performatividade dos corpos reunidos e as possibilidades que esse espaço engendra em sua constituição. Isso "exige que se invada o regime de espaço estabelecido com um conjunto de suportes materiais que sejam tanto mobilizados como mobilizadores" (ibidem: 93). Os corpos reunidos só podem agir, deste modo, quando suportados pelo espaço construído e seus suportes materiais, que intervêm na organização espacial do poder.

Esta abordagem toma como prioritária a materialidade da constituição desses espaços como, por exemplo, a iluminação, a configuração das paredes, as cores, os lugares em que as fotografias são incentivadas ou não, a presença de cenários e objetos mobilizadores, entre outras formas de consumo possíveis desses espaços de aparição. Aqui, o suporte material da comunicação - nesse caso, o espaço constituído e os incentivos físicos que ele oferece para a aparição dos sujeitos - não apenas influenciam, mas determinam a mensagem, ao mediar "a materialidade de um movimento corporal imposto pelo meio" (Gumbrecht, 2010).

Alguns espaços são organizados de forma a permitir certas visibilidades e proibir outras, a partir de instâncias normativas diversas. O que deve aparecer e o que não deve - e, principalmente, os atores que são autorizados a "performar" em certos espaços de aparição e os que não o são - são sintomáticos da distribuição de valores dessa instituição em sua própria reivindicação do espaço público.

As possibilidades de consumo de espaços de aparição, nesse sentido, estão coadunadas com as formas como os espaços são institucionalmente construídos de forma a permitir certas ações de visibilização e proibir outras. 
Consumir tais espaços significa estar urdido à delimitação de campos de reconhecimento de certos tipos de subjetividade em detrimentos de outros - inclusive em questões de gênero.

Considerar o espaço dessa forma significa desvinculá-lo da ideia de que ele é um suporte para as ações comunicacionais, e passar a considerá-lo como a materialidade que permite os diversos processos interativos de consumo de instâncias de aparecimento.

[E]studar o espaço como territorialidade significa apreender o modo como, através das espacialidades, se pode ler e interpretar a cultura [...] [de modo que] somos obrigados, portanto, a "estranhar" o cotidiano que nos envolve nas espacialidades corriqueiras e a desenvolver, sobre elas, uma crítica que deve prever ações e consequências a fim de iluminar a cultura. (Ferrara, 2008: 59-60)

Por conseguinte, podemos dizer que consideramos a Igreja Hillsong como um espaço de consumo de aparição articulador de visibilidades de gênero. A primeira parte desta afirmação - a de que a instituição se constitui como um espaço de consumo de aparição - se deve ao fato de que o próprio espaço da Igreja é constituído para que seus fiéis tirem fotografias, compartilhem conteúdos e ajam como consumidores de um espaço feito para aparecer. Como o Instagram se constitui como uma das principais estratégias de ferramentas de comunicação da Hillsong, muitos espaços físicos da Igreja são estrategicamente articulados com o intuito de o participante tirar fotografias bonitas e agradáveis e, com isso, mostrar sua devoção.

Já a segunda parte - a de que esse espaço é não apenas vinculado ao consumo da aparição, mas também como articulador de visibilidades de gênero - diz respeito ao fato de que o consumo desse espaço não se dá de maneira igualitária entre homens e mulheres, uma vez que as possibilidades de consumo desse espaço de aparição engendram também pedagogias de comportamento esperadas para homens e mulheres fiéis. Para que possamos discutir isso, iremos apresentar, em um primeiro momento, os ideais e pressupostos da Hillsong para, na sequência, analisarmos, a partir das estratégias comunicacionais articuladas em seu espaço, as possibilidades diferenciais de consumo desses espaços de aparição entre os homens e as mulheres nesta Igreja. 


\section{O que é a Igreja Hillsong e por que ela engendra um espaço de consumo de aparição?}

Em uma reportagem publicada em agosto de $2019,{ }^{2}$ a BBC definia a Igreja Hillsong como a "que atraiu Justin Bieber e outros astros usando shows de rock e Instagram”. Isso porque a agremiação reúne os preceitos das igrejas pentecostais tradicionais a um modo de apresentação voltada principalmente para o público jovem que combina a presença de personalidades famosas, músicas pop e um uso agressivo de estratégias de comunicação a partir de redes sociais e aplicativos.

A Igreja é fundada em 1983 pelo casal Brian e Bobbie Houston, com o nome de Hills Christian Life Center, em Baulkham Hills (Sydney, Austrália). O nome muda para Hillsong Church em 2001, em função do sucesso obtido pelas bandas ligadas à agremiação, que combinavam pregação religiosa com música pop. É fundada a primeira sede em São Paulo em 2016, no prédio do Audio Club. Após dois meses, mudam as instalações físicas para outra casa de espetáculos, o Villaggio JK.

Desde esse período, é possível perceber uma expansão crescente: a Hillsong iniciou suas atividades em São Paulo com uma reunião e, em 2019, contava com cinco cultos e 4000 frequentadores a cada domingo. Percebemos seu crescimento nas redes sociais digitais, principalmente no Instagram, que, em 2019, contava com 148 mil seguidores. Escolhemos esta Igreja como objeto de estudo em função de sua estratégia de comunicação baseada em redes sociais e aplicativos.

Goh (2008) situa a Hillsong no movimento das megaigrejas - congregações que, principalmente a partir dos anos 2000, estabeleceram filiais em diversos países e se distinguem das igrejas mais antigas por

um estilo de culto contemporâneo com destaque para instrumentos musicais e mídias eletrônicas, oradores dinâmicos e carismáticos, serviços voltados mais para "buscadores" do que para crentes maduros, redes internacionais e informalidade nos trajes e na atmosfera. (ibidem: 285$)^{3}$

Os seus membros são, em sua maioria, jovens com alto poder aquisitivo e bons níveis de formação (Goh, 2008). Para Yip (2015), a Hillsong desestabiliza as conceptualizações tradicionais da religião ao unir imagens seculares

\footnotetext{
${ }^{2}$ Honderich, Holly (2019), "A igreja que atraiu Justin Bieber e outros astros usando shows de rock e Instagram”, BBC News Brasil, 21 de agosto. Consultado a 21.02.2020, em https://www.bbc.com/ portuguese/internacional-49405473.

${ }_{3}$ Todas as traduções são livres e da responsabilidade dos autores.
} 
a signos da cultura popular, de forma a produzir discursos, artefatos e experiências que encontram ressonância em ideais das culturas de consumo.

No site da Hillsong está disponível um texto intitulado "A Igreja que agora vejo", assinado por Brian Houston. ${ }^{4}$ Nele, o fundador da Igreja explica alguns dos preceitos da religião e, em um determinado ponto, afirma que vê "uma igreja comprometida com uma rede inovadora que conecta centenas de milhares de pastores e líderes, e os equipa para florescerem”, ou seja, "[u]ma rede comprometida com a unção de apostolado de líderes que são insaciáveis para ver a Igreja de Jesus Cristo se levantar e viver toda a vida que ela tem para viver". Embora a palavra "rede" assuma aqui um caráter religioso, a ação estratégica de comunicação da Hillsong deixa entrever que se trata também de uma rede de comunicação. Além de uma estratégia agressiva de mobilização de fiéis a partir da divulgação em redes sociais, a sede da Igreja possui uma série de espaços projetados para que seus fiéis possam tirar fotografias de suas participações nos cultos.

As redes de comunicação são urdidas às estratégias religiosas da agremiação, deixando pressupor que

o "religioso" (aquilo que é relativo ou próprio da religião) é mediação presente nos diferentes processos comunicacionais midiáticos: no jornalismo, na literatura, na música, no entretenimento, na publicidade [...] [de forma que] a religião se manifesta nas abordagens não-religiosas, o que passa pela compreensão das significações imaginárias, das representações socioculturais tanto no processo de produção quanto no de recepção. (Cunha, 2016)

Assim sendo, constata-se que a distribuição de espaços de aparição é uma dimensão importante das estratégias comunicacionais da Hillsong.

É possível encontrar uma série de falas públicas dos líderes da Igreja que falam sobre a igualdade entre homens e mulheres. Em uma entrevista dada em 2010, por exemplo, Bobbie Houston afirma: "em nossa experiência como igreja, ter mulheres na liderança nunca foi um problema". ${ }^{5}$ As possibilidades de consumo de tais espaços, contudo, são distribuídas de forma diferencial entre os fiéis - especialmente quando analisadas sob a perspectiva de um recorte de gênero. Em um estudo anterior sobre a Hillsong, Miller (2016) já

\footnotetext{
${ }^{4}$ Consultado a 20.05.2020, em https://hillsong.com/brazil/pt/saopaulo/visao/.

5 Parker, Stephanie (2017), “'God's True Intent Has Been Distorted': Hillsong Church Co-Founder Explains Her Strong Support for Women in Church Leadership Roles”, Faithwire, 8 de maio. Consultado a 01.09.2021, em https://www.faithwire.com/2017/05/08/exclusive-hillsong-churchco-founder-bobbi-houston-talks-to-faithwire-about-navigating-life-challenges-and-women-inleadership/.
} 
afirmara que, embora as mulheres pentecostais e carismáticas da Austrália (berço da congregação estudada) tenham experimentado amplas mudanças sociais no que se refere às maneiras como participam da sociedade, seus papéis em igrejas como a Hillsong não mudaram de maneira semelhante, de forma que as principais posições de liderança ainda são ocupadas por homens e ainda há o espectro de uma teologia da submissão que limita o papel que elas desempenham na Igreja. No presente artigo, iremos discutir como tal se manifesta na constituição do espaço no interior da Hillsong, a partir das possibilidades diferenciais de consumo de espaços de aparição entre os gêneros.

Em instituições religiosas, são muitos os espaços de aparição possíveis: cultos, eventos, produções midiáticas como blogues, sites e perfis de redes sociais, entre outros. Aqui, contudo, optamos por um recorte específico: para que possamos estudar isso, elegemos como corpus empírico as publicações feitas no perfil do Instagram da Hillsong São Paulo ao longo do ano de 2019. ${ }^{6}$ São, ao todo, 364 posts no período. Iremos observar a forma como o espaço da Hillsong é representado nessas imagens. Acreditamos que as representações postadas no Instagram são objetos de estudo interessantes, uma vez que implicam escolhas feitas pela própria Hillsong em como veicular os seus ambientes internos - trata-se, portanto, de materializações das estratégias da instância da produção a respeito de como esses lugares devem ser divulgados.

Lembramos que, para Butler (2019), a mediação da performatividade própria da assembleia pode se dar tanto em espaços físicos quanto virtuais, uma vez que as formas de veiculação pública desses espaços não são apenas um evento, mas também uma característica que compõe o espaço performático de visibilidades. Isso porque a potência do espaço se manifesta, principalmente, quando suas dimensões visuais e audíveis podem ser estendidas e replicáveis para além do espaço físico considerado. Em outros termos, "a mídia constitui a cena em um tempo e um lugar que incluem e excedem a sua instanciação local" (ibidem: 101). E assim, "aqueles que estão em outro lugar têm a sensação de que estão obtendo algum acesso direto por meio das imagens e dos sons que recebem" (ibidem). O fato de as instituições sociais estabelecerem arranjos espaciais para "tornar visíveis as ações e os acontecimentos" de acordo com os seus próprios valores é, portanto, "uma estratégia explícita por parte daqueles que bem sabem ser a visibilidade mediada uma arma possível no enfrentamento das lutas diárias" (Thompson, 2008: 16).

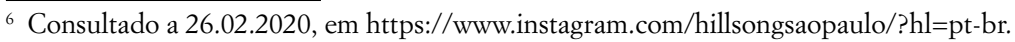


Para que pudéssemos analisar a grande quantidade de posts publicados na página de Instagram da Hillsong São Paulo ao longo do período analisado, os mesmos foram divididos em categorias específicas de análise. A maior parte das fotografias publicadas pode ser dividida em três categorias de conteúdo específicas, a saber: 1) as fotografias de pregação (86 imagens), que mostram os pastores atuando no palco da igreja, com um microfone na mão; 2) as fotografias que individualizam fiéis ou pequenos grupos de fiéis orando nos cultos (90 imagens); 3 ) as fotografias de divulgação de eventos específicos promovidos pela Igreja (188 imagens). Nesta terceira categoria, é possível observar eventos que são direcionados especificamente para homens ou para mulheres (como o Dia dos Pais ou Dia das Mães), que perfazem 37 posts - serão analisadas apenas as publicações referentes a eventos com essa divisão de gênero. A análise dessas imagens revela aspectos importantes das estratégias comunicacionais da Hillsong, que materializam e dão visibilidade às possibilidades diferenciais do consumo de espaços de aparição de homens e mulheres no interior da Igreja.

Quanto ao arcabouço metodológico de tratamento dos dados, iremos analisar o espaço representado nessas imagens sob a perspectiva metodológica da $\mathrm{ACD}$, que trata não apenas das formações discursivas, mas dos acessos discursivos, entendidos como as possibilidades diferenciais que os grupos sociais têm de ingresso, participação e manutenção do domínio discursivo. Para van Dijk (2010), as instâncias de interesse da ACD são: o acesso ao discurso (entendido como a instância dos atores que têm direito a produzir um determinado discurso e controlar o seu acesso), os poderes e limitações do grupo que discursa (ou controlo da forma como os tópicos devem ser discutidos e enquadrados) e as limitações de controle (alcance da interpretação preferencial do discurso). No presente trabalho, a análise estará direcionada para os elementos que são externos ao discurso, mas que delimitam suas condições de produção a partir das possibilidades de performance ou de ritual no evento. Iremos observar a forma como a própria constituição do espaço na Hillsong permite o engendramento de possibilidades de visibilidade diferenciadas para homens e mulheres.

A partir deste arcabouço metodológico é possível argumentar a possibilidade de dissonância entre a abordagem performativa de Butler (sustentada numa perspectiva de ato de fala, de uma agência num "aqui e agora") e a abordagem crítica de discurso proposta por van Dijk, que pressupõe um acesso a discursos pré-existentes. Sobre este aspecto, esclarecemos que, para Butler, a constituição de gênero não é independente das formações discursivas. Em A vida psíquica do poder: teorias da sujeição, Butler endereça a questão sob a perspectiva do assujeitamento foucaultiano, que "consiste 
precisamente nessa dependência fundamental de um discurso que nunca escolhemos mas que, paradoxalmente, inicia e sustenta nossa ação". Posto que a sujeição significa "tanto o processo de se tornar subordinado pelo poder quanto o processo de se tornar sujeito" (2017 [1997]: 10), a formação do sujeito é dependente da ação do discurso de duas maneiras: "como o que torna o sujeito possível, como condição de sua possibilidade e ocasião formativa" e "como o que é retomado e reiterado no 'próprio' agir do sujeito" (ibidem: 22). Na leitura da autora, os discursos pré-existentes não se investem no sujeito de uma só vez, mas sim, na iterabilidade de ações que se tornam repetíveis no cotidiano, no aqui e agora, e, como tal, podem também ser subvertidos pelo sujeito. Assim, de acordo com Butler (ibidem: 24), "para que as condições de poder persistam, elas devem ser reiteradas" e "o sujeito é justamente o local de tal reiteração, uma repetição que nunca é meramente mecânica”.

Ainda sobre este aspecto, é importante esclarecer que partimos do pressuposto de que "os discursos se revelam em seus efeitos, a saber, nas materialidades que produzem” (Gomes, 2019: 271) em lugares como ambiências midiáticas. Assim, o discurso "traz consigo um entendimento de como o mundo 'funciona' e, portanto, um entendimento de como as sociedades e os indivíduos devem responder a esse funcionamento" (ibidem: 273), a partir de agenciamentos diversos. As fotografias do perfil de Instagram da Hillsong podem ser entendidas como exemplos dessas materialidades que são urdidas por diferentes discursos sobre gênero e articulam possiblidades de espaços de aparição. Esses discursos estão articulados em tais materialidades a partir de iterabilidades diversas que, a cada repetição, produzem sujeitos - uma produção que não se dá em sua totalidade instantaneamente, mas sim repetidamente. "É precisamente a possibilidade de uma repetição que não consolida essa unidade dissociada, o sujeito, mas que prolifera efeitos que debilitam a força da normalização" (Butler, 2019: 100). Ou, em outros termos, "o sujeito foucaultiano nunca está totalmente constituído na sujeição, mas nela se constitui repetidamente", posto que "é na possibilidade de uma repetição que se repete contra sua origem que a sujeição adquire seu poder involuntariamente habilitador" (ibidem: 101).

Observar o consumo de espaços de aparição a partir dessa perspectiva, no entrecruzamento entre Butler e van Dijk, é estudar como essa iterabilidade discursiva sobre gênero se materializa nessas constituições espaciais midiatizadas e como elas engendram formas diferenciais de aparição - que se estruturam em torno de discursos pré-existentes, cuja iterabilidade é um elemento importante tanto de manutenção de sua estrutura quanto de redesenho de seus espaços. 


\section{As possibilidades diferenciais de consumo do espaço de aparição entre os gêneros}

Para van Dijk (2010: 89), um elemento importante na reprodução discursiva do poder é o próprio acesso ao discurso e aos eventos comunicativos, pelo que a análise deve se voltar para "quem pode falar e escrever para quem e em que contexto ou quem pode participar desses eventos comunicativos nos mais variados papéis", falante ou ouvinte. Isso porque "podemos supor que, como acontece com outros recursos sociais, mais acesso - de acordo com esses vários papéis de participantes - corresponde a mais poder social", ou seja, "as medidas de acesso ao discurso podem ser indicadores bastante confiáveis de poder de grupos sociais e de seus membros" (ibidem). Nas imagens publicadas no Instagram da Hillsong São Paulo durante o ano de 2019, é possível analisar os atores que controlam os eventos comunicativos a partir dos papéis comunicacionais ocupados, em um recorte de gênero. A análise está direcionada, portanto, para os espaços ocupados, no interior da Igreja, por homens e mulheres - demonstrando como os espaços físicos representados nas imagens se revertem em papéis comunicacionais.

A partir das fotografias publicadas é possível notar que, na Hillsong, o palco é um espaço eminentemente masculino. Muito embora os líderes da Igreja sejam casais - no caso, Brian e Bobbie Houston como pastores seniores e Chris e Lucy Mendez como pastores líderes - constata-se que a maior parte das imagens mostra apenas os homens no ato da pregação (de microfone na mão, em frente a uma audiência de fiéis). Das 86 imagens publicadas com essa temática no perfil do Instagram da Hillsong São Paulo, os homens figuram sozinhos em 69 delas $(80,2 \%$ das imagens publicadas) enquanto as pastoras estão sozinhas no palco em apenas oito (9,3\%). Nas restantes fotografias publicadas $(10,5 \%)$ é possível observar homens e mulheres a aparecerem juntos no palco. O espaço do púlpito, portanto, articula-se majoritariamente como um espaço masculino - o que também pode ser confirmado se considerarmos os episódios de podcasts disponibilizados pela Hillsong São Paulo em 2019: 62 deles (94\%) são pregações narradas por homens e apenas quatro $(6 \%)$ são proferidas por mulheres.

As fotografias que dão destaque aos fiéis, contudo, mostram outro tipo de retrato: as pessoas em evidência em seus atos de fé são, principalmente, mulheres. Das 90 imagens publicadas sobre esse tema, $52(57,7 \%)$ isolam mulheres em seus atos de fé; 20 (22,2\%) destacam homens e $18(20,1 \%)$ retratam homens e mulheres. Assim, enquanto o espaço de visibilidade da liderança na pregação é dado majoritariamente a homens, a presença nos cultos como fiéis dá destaque à participação feminina. Os homens ocupam, 
predominantemente, os espaços físicos da igreja relacionados à fala, e as mulheres, por sua vez, os lugares reservados à escuta.

Como interdiscurso subjacente a essa materialização das relações de gênero nas fotografias, podemos observar um forte ideal de liderança masculina na condução do culto. Conforme apontado por Ecco (2008: 93), nas "expressões religiosas oriundas da tradição cristã há muita ênfase na manutenção da supremacia masculina”, materializada em uma figura masculina de Deus, mantenedora da vinculação simbólica entre masculinidade e liderança, "onde o homem exerce a supremacia na condução ministerial e doutrinal". Isso se manifesta nas imagens publicadas no perfil de Instagram da Hillsong que materializam um esquema discursivo e comunicativo de estratégias de acesso a partir das modalidades de participações que colocam o masculino prioritariamente no papel do orador e o feminino prioritariamente no lugar do ouvinte.

A aparição dos pastores não conota apenas lugares de liderança, mas também, projeções aspiracionais de como os fiéis devem se comportar. $\mathrm{Na}$ Hillsong, o casal de pastores "são 'marcas' transcendentes, objetos de inspiração, aspiração e emulação, ao invés de personificações de autoridade e restrição religiosa" (Wade, 2010: 43). Eles apresentam-se como ideais de sucesso na carreira moral proposta pela congregação e, portanto, como ideais de gênero a serem compartilhados pela comunidade. Tais representações do espaço nas fotografias em análise engendram lugares majoritariamente ocupados por essas figuras aspiracionais, mimetizando os lugares comunicativos que, simbolicamente, devem ser ocupados pelos fiéis, articulando visibilidades de gênero bastante específicas a partir da ocupação de um espaço físico.

Outro elemento de análise apontado por van Dijk (2010: 92) é a forma como o cenário dos eventos comunicativos pode ser controlado por diferentes atores. Isso diz respeito não apenas ao que pode ser decidido pelos participantes que controlam a interação - "a quem é chamado ou obrigado a participar e em qual papel” -, mas principalmente às circunstâncias e aos "apoios de poder (o banco e a toga de um juiz, o uniforme dos policiais ou a cadeira na ponta da mesa)" que integram o evento. Na Hillsong, tais elementos vinculados aos "apoios de poder" fazem parte do rito litúrgico, de forma que a congregação investe na constituição de um cenário agradável e bonito para seus fiéis a partir da decoração da igreja e dos objetos que fazem parte do culto. Eles funcionam como suportes materiais mobilizadores (Butler, 2019) das reuniões e permitem uma análise de cenário, sob a perspectiva do recorte de gênero. Nos posts de Instagram relativos aos eventos específicos para homens e mulheres, é possível observar como esses 
objetos engendram diferentes formas a partir das quais a Hillsong mobiliza esses apoios de poder. Os mais relevantes são as reuniões do Dia das Mães e do Dia dos Pais, bem como os dias reservados para a Sisterhood e para o Evento de Homens.

Em 2019, em São Paulo, a reunião Sisterhood aconteceu nos dias 9 de março, 22 de junho, 30 de agosto e 22 de novembro e, segundo o site da instituição, "Sisterhood são momentos em que as mulheres de nossa igreja se reúnem para um tempo incrível! Adoração, conexão e uma palavra inspiradora para mulheres de todas as idades. Todas são bem-vindas". A pastora Lucy Mendez participa nessas ocasiões "para compartilhar uma mensagem especial para todas as nossas meninas e mulheres". Para o público masculino, há o "Evento de Homens" que, segundo o site da Igreja, é "um lugar onde homens se reúnem para serem inspirados, equipados, desafiados e renovados para o futuro. Será um tempo inesquecível juntos como amigos, pais, filhos e irmãos para crescermos em tudo o que Deus tem para nós." ${ }^{8}$

Tais eventos são interessantes na medida em que existe, neles, "a incorporação de elementos midiáticos na composição litúrgica e arquitetônica dos espaços físicos do culto" (Klein, 2006: 139), materializados em elementos de "apoios de poder" (nas palavras de van Dijk) ou "suportes materiais mobilizadores" (se preferirmos os termos de Butler) que engendram a constituição de uma visibilidade específica para homens e para mulheres incrustada na própria espacialidade do evento.

Um desses suportes materiais mobilizadores pode ser observado na constituição de espaços instagramáveis: estruturações espaciais visualmente atraentes "como, por exemplo, restaurantes e bares que modificaram seus ambientes e cenários para se tornarem potencialmente fotografáveis, [...] com o objetivo de serem publicados nos mais diversos perfis" (Andrade e Oliveira, 2020). Na Hillsong, tais espaços são bastante valorizados e, nos eventos anteriormente referidos, articulados de maneira a incorporar-se às visualidades permitidas para homens e para mulheres. Nas imagens de divulgação dos eventos, é possível observar que tais espaços instagramáveis possuem signos masculinos e femininos estereotipicamente demarcados: nos eventos da Sisterhood e do Dia das Mães, podemos observar corações e flores; nos Eventos de Homens, motocicletas e mesas de sinuca.

Nesses eventos, outros suportes materiais mobilizadores são urdidos nos espaços de ação possibilitados em cada um deles para além do culto:

\footnotetext{
${ }_{7}$ Consultado a 26.02.2020, em https://hillsong.com/pt/sao-paulo/event/2019/06/sisterhood-nahillsong-sao-paulo/\#.Xla5U2hKjIU.

${ }^{8}$ Consultado a 26.02.2020, em https://hillsong.com/pt/saopaulo/eventodehomens2019/.
} 
em conjunto com a pregação litúrgica, são oferecidas aos participantes outras atividades. No caso dos eventos para as mulheres, são disponibilizados cabeleireiros, manicures e massagistas; para os homens, a simulação de um parque de diversões com videojogos, touro mecânico e máquinas de basquete eletrônicos, tudo documentado através de vídeos publicados no Instagram da Hillsong São Paulo.

O uso de signos de gênero estereotipicamente marcados é confirmado, ainda, nas peças de divulgação presentes no Instagram. Na convocação para o encontro do Dia das Mães, é possível ver imagens de mulheres brincando com os seus filhos e, no final, aparece a mensagem "Tem que ser amor". Para o Dia dos Pais, a interação de homens com as crianças fornece pano de fundo para o desfile das palavras "Amigo", "Professor", "Companheiro", "Conselheiro", "Protetor", "Legado", "Experiência”, "Exemplo".

Esses suportes materiais mobilizadores organizam o espaço a partir da demarcação de papéis de gênero, de forma que o empoderamento feminino é vinculado a signos de beleza (como maquiagem, cabelo bonito, etc.) e o masculino a palavras de ordem (como liderança, valentia e ação), em práticas que implicam possibilidades diferenciais de aparecimento do corpo masculino e feminino no espaço comunicativo. Os estereótipos de gênero não estão incrustados na fala dos pastores ou nos materiais impressos, mas na própria constituição espacial dos elementos mobilizadores dos cultos.

A partir das maneiras em que a Hillsong escolhe representar os seus espaços internos em sua página do Instagram, é possível observar a materialização de uma lógica espacial de delimitação de possibilidades diferenciais de consumo dos espaços de aparição em relação aos gêneros. $\mathrm{O}$ uso de signos estereotipicamente marcados de feminino e masculino em seus espaços de aparição bem como a demarcação de papéis de oradores e ouvintes deixam entrever que as tais representações espaciais operam como uma solicitação moral. Isso significa que, a partir das imagens desses espaços de aparição autorizados para homens e mulheres, os fiéis são "afrontados por alguma coisa que está além da [...] vontade" individual, que "chega de fora, como uma imposição, mas também como uma reivindicação ética" de materialização de valores abstratos (Butler, 2019: 113). Trata-se de uma relação ética mediada a partir da qual, independentemente do conteúdo do discurso, o sujeito é interpelado a partir de um endereçamento constituído no próprio consumo do espaço de aparição e convocado para uma forma específica de ação a partir dos suportes mobilizadores deste espaço.

A lógica espacial de possibilidades de aparição na Hillsong pode ser interpretada a partir de dois eixos: como um elemento que engendra um endereçamento e como um componente que mobiliza uma ação. Ao articular 
um endereçamento, é o próprio espaço que atua como elemento convocatório para que o consumidor desse ambiente assuma certas performatividades de gênero que estabelecem uma partilha entre os padrões corpóreos e de comportamento que podem aparecer e os que não podem. O próprio espaço constitui-se como um "mapa cognitivo" que orienta "agires no mundo" a partir de objetos mobilizados do espaço, que atuam como "cadeia significante em que vários significantes flutuantes são encadeados, [sendo que] num dado ponto o enunciador realiza uma costura significante, a fim de se produzir uma totalização parcial do discurso" (Prado, 2009: 39). Para além do conteúdo do discurso, é o próprio espaço que endereça um modo de partilha genérica ideal ao indicar "caminhos modalizados" que, se ocupados pelos fiéis, enunciam "lugares de pertencimento e reconhecimento desejados e anunciados como repletos de valores positivos" (ibidem).

Trata-se, também, do engendramento de uma ação. Butler (2019: 99) chama a atenção para o fato de que as possibilidades de articulação política de um espaço não se estruturam apenas a partir de grandes ações, mas também a partir de micro-ocupações. Para a autora, o simples ato de consumo desse espaço de aparição é uma eloquente declaração política e moral - "e deve até mesmo contar como uma ação", pois os corpos que agem juntos "reivindicam um determinado espaço como público", de forma que "o próprio caráter público do espaço está sendo questionado ou até mesmo disputado" quando esses corpos se reúnem (ibidem). A Hillsong, ao organizar um espaço diferencial de aparição consoante o gênero, está ciente de que a própria reunião desses corpos em um espaço de assembleia (determinado por configurações materiais) é um posicionamento em relação a um conjunto de valores estabelecidos, a reivindicação e a defesa de um conjunto de pressupostos éticos que urde a sociabilidade pregada pela Igreja. Trata-se de um modo não apenas de ocupar o espaço público, mas de defender os seus valores a partir de uma articulação de um espaço físico material. "Ao mesmo tempo, esses ambientes materiais são parte da ação, e eles mesmos agem quando se tornam a base para a ação" (ibidem: 81), ou seja, articulam um instrumento de reivindicação do espaço público e de comunicação de valores de gênero.

Os espaços diferenciais de aparição na Hillsong são, assim, não apenas um modo de organização dos corpos em assembleia, mas um conjunto vivo de relações, que performativamente instrumentaliza os modos de aparição autorizados.

\section{Considerações finais}

Conforme discutimos ao longo do texto, a partir das reflexões de Butler (2019), a visibilidade é uma dimensão importante das políticas de 
reconhecimento, de forma que as possibilidades diferenciais de aparição na esfera pública estão articuladas com as maneiras pelas quais percebemos os papéis de gênero em instituições sociais específicas. E isso se articula não apenas a partir do conteúdo que é compartilhado por essas instituições, mas também nas formas possíveis de ocupação de um espaço (seja físico ou virtual) criado por elas. Tais articulações espaciais engendram formas de aparecimento autorizadas ou negadas que muitas vezes são contraditórias em relação às mensagens verbais emitidas.

No plano dos conteúdos, é possível observar que as pregações da Hillsong, em inúmeras ocasiões, afirmam a igualdade entre homens e mulheres. Em maio de 2017, para citar apenas um exemplo, a pastora Bobbie Houston disse em uma entrevista que "através da história, através da cultura, e através dos obstáculos do tempo, a verdadeira intenção de Deus foi distorcida [...]. Se voltarmos aos primórdios, lá no começo do mundo, Deus nos criou macho e fêmea e Ele falou de homens e mulheres juntos".

Um olhar mais detido sobre as lógicas de representação do espaço, contudo, revelam que há possibilidades diferenciais de consumo de espaços de visibilidade entre homens e mulheres, que materializam sociabilidades próprias, vinculadas a papéis de gênero demarcados e desiguais entre si. Os espaços de visibilidade articulados pela Hillsong podem ser interpretados como espaços morais de aparição de gênero, na medida em que marcam uma partilha entre formas de comportamento e de estilos de vida legitimados ou não pela doutrina.

No perfil de Instagram da Hillsong, as possibilidades de consumo dos espaços de aparição são diferentes para homens e para mulheres - o que demonstra como o espaço é performaticamente construído a partir da iterabilidade de um discurso de gênero que é materializado nas fotografias dos fiéis ao ocuparem esses espaços. O direito de aparecer é diferencialmente proposto em relação a homens e mulheres nesse espaço de divulgação oficial da Igreja. Nas fotografias, é possível observar a mobilização de suportes materiais que intervêm na organização espacial (posicionamento de corpos, objetos, espaços instagramáveis, entre outros) que permitem certas visibilidades e proíbem outras, a partir de instâncias normativas de gênero.

\footnotetext{
${ }^{9}$ Parker, Stephanie (2017), “'God's True Intent Has Been Distorted': Hillsong Church Co-Founder Explains Her Strong Support for Women in Church Leadership Roles”, Faithwire, 8 de maio. Consultado a 06.03.2020, em https://www.faithwire.com/2017/05/08/exclusive-hillsong-churchco-founder-bobbi-houston-talks-to-faithwire-about-navigating-life-challenges-and-women-inleadership/.
} 
Isso fica evidente no material empírico analisado ao longo do artigo. $\mathrm{Na}$ maior parte das fotografias publicadas, o espaço do púlpito é ocupado por homens e o da audiência, por mulheres - de forma a que os homens ocupam os espaços da fala (vinculados a um ideal de liderança masculina na condução do culto) e, as mulheres, os da escuta. Isso também se manifesta na articulação dos espaços instagramáveis, que possuem objetos estereotipicamente relacionados ao masculino (e.g., mesas de sinuca) e ao feminino (e.g., utensílios para manicure) como suportes materiais mobilizadores - que organizam o espaço a partir da demarcação de papéis de gênero.

No que se refere às delimitações desses papéis, Butler (2019:71) assume que "os nomes pelos quais somos chamados são tão importantes para a performatividade quanto os nomes pelos quais nos chamamos", uma vez que "temos que identificar as convenções que operam em um amplo conjunto de estratégias de designação de gênero". Tais denominações, contudo, nem sempre estão no plano dos conteúdos que engendram os discursos, encontrando-se também na constituição dos próprios espaços que abrigam as mais diversas práticas sociais. As possibilidades diferenciais de consumo de espaços de aparição de gênero são, assim, elementos convocatórios que endereçam modos de comportamento e convocam para uma ação determinada em um espaço público.

Revisto por Ana Sofia Veloso

\section{Referências bibliográficas}

Andrade, Matheus José Pessoa de; Oliveira, Tassyara Onofre de (2020), "Letreiros e amores: uma estratégia informacional para existir no Instagram”, Anais do II Workshop de Informação, Dados e Tecnologia. Paraíba: UFPB. Consultado a 05.03.2020, em http://dadosabertos.info/enhanced_publications/idt/papers/9.pdf.

Busin, Valéria (2011), "Religião, sexualidades e gênero”, Rever, 11(1), 105-123.

Butler, Judith (2017), A vida psíquica do poder. Teorias da sujeição. Belo Horizonte: Autêntica. Tradução de Rogério Bettoni [ed. orig. 1997].

Butler, Judith (2019), Corpos em aliança e a politica das ruas: notas para uma teoria performativa de assembleia. Rio de Janeiro: Civilização Brasileira. Tradução de Fernanda Siqueira Miguens [ed. orig. 2015].

Cunha, Magaly (2016), "Elucidações contemporâneas nos estudos brasileiros em mídia e religião: a perspectiva das mediações culturais e comunicacionais”, Famecos, 23(2), s.p.

Ecco, Clóvis (2008), “A função da religião na construção social da masculinidade”, Phenomenological Studies, XIV(1), 93-97. 
Ferrara, Lucrécia (2008), Comunicação, espaço, cultura. São Paulo: Annablume.

Goh, Robbie (2008), "Hillsong and 'Megachurch' Practice: Semiotics, Spatial Logic and The Embodiment of Contemporary Evangelical Protestantism”, Material Religion, 4(3), 284-304.

Gomes, Mayra (2019), “As materialidades e seus discursos”, Comunicação, Mídia e Consumo, 16(46), 271-290.

Gumbrecht, Hans Ulrich (2010), "O campo não hermenêutico ou a materialidade da comunicação”, Teresa: Revista de Literatura Brasileira, 10(11), 386-407. Tradução de João Cezar de Castro Rocha [ed. orig. 1993].

Klein, Alberto (2006), Imagens de culto e imagens da mídia. Porto Alegre: Sulina.

Machado, Maria das Dores Campos (2005), "Representações e relações de gênero nos grupos pentecostais”, Estudos Feministas, 13(2), 387-396.

Miller, Elizabeth (2016), "Women in Australian Pentecostalism: Leadership, Submission, and Feminism in Hillsong Church", Journal for the Academic Study of Religion, 29(1), 52-76.

Prado, José Luiz Aidar (2009), “Experiência e receituário performativo na mídia impressa”, Intexto, 20(1), 34-47.

Thompson, John (2008), “A nova visibilidade”, Matrizes, 1(2), 15-38. Tradução de Andrea Limberto.

van Dijk, Teun (2010), Discurso e poder. São Paulo: Contexto. Tradução de Judith Hoffnagel e Karina Falcone [ed. orig. 2008].

Yip, Jeaney (2015), "Marketing the Sacred: The Case of Hillsong Church", in Jonathan D. James (org.), A Moving Faith: Mega Churches Go South. London: SAGE, 106-126. Wade, Matthew (2010), The Institution, The Ethic, and The Affect: The Hillsong Church and the Production of Multiple Affinities of the Self. Acton: College of Arts \& Social Sciences, Australian National University.

\section{Eliza Bachega Casadei}

Programa de Pós-graduação em Comunicação e Práticas de Consumo, Escola Superior de Propaganda e Marketing

Rua Dr. Álvaro Alvim, 123 - Vila Mariana, São Paulo - SP, 04018-010, Brasil

Contacto: elizacasadei@yahoo.com.br

ORCID: https://orcid.org/0000-0003-2810-8702

\section{Andrey Albuquerque Mendonça}

Escola Superior de Propaganda e Marketing (ESPM) I PRECE - Programa de Estudos em Religião e Consumo, ESPM

Rua Dr. Álvaro Alvim, 123 - Vila Mariana, São Paulo - SP, 04018-010, Brasil.

Contacto: andrey.mendonca@espm.br

ORCID: https://orcid.org/0000-0002-6925-0572 
Artigo recebido a 19.05.2020

Aprovado para publicação a 20.09.2021

https://doi.org/10.4000/rccs. 12455

\section{Possible Ways to Consume Spaces of Appearance, Gender-Based Shares and Performances}

Based on a reflection that examines the constitution of space as an important consideration in the struggle for recognition, the objective of this article is to study the differential possibilities regarding the consumption of spaces of appearance for men and women at Hillsong Church. We will analyze how an individual's religious values will materialize to a lesser extent in terms of gender in the expressive content than in the performativity of space constitution in which gender can be expressed. We will use critical discourse analysis to study space from a gender representation perspective through images published on Hillsong São Paulo's Instagram profile in 2019. The differential spaces of appearance at Hillsong Church are not only a way of organizing bodies in assemblies, but a living set of relationships, which performatively instrumentalizes the authorized modes of appearance and can be interpreted as moral spaces of gender appearance.

Keywords: gender inequality; gender representation; religious institutions; religious practices.

\section{Possibilités de consommation des espaces d'apparition, partages de genre et performativités}

À partir d'une réflexion sur la constitution de l'espace comme champ de luttes pour la reconnaissance, l'objectif de cet article est d'étudier les possibilités différentielles de consommation des espaces d'apparition pour les hommes et les femmes à l'Église Hillsong. Nous analyserons comment leurs valeurs religieuses en rapport avec les genres se matérialisent moins dans le contenu de l'énonciation que dans la performativité de la constitution des espaces dans lesquels le genre peut être énoncé. En utilisant l'analyse critique du discours, nous étudierons la représentation des espaces dans les images publiées en 2019 sur le profil Instagram de Hillsong São Paulo à partir d'une perspective de genre. Les espaces différentiels d'apparition dans cette Église ne sont pas seulement une manière d'organiser les corps en assemblée, mais un ensemble vivant de relations, qui instrumentalisent performativement les modes d'apparition autorisés et peuvent être interprétés comme des espaces moraux d'apparition du genre.

Mots-clés: inégalité de genre; institutions religieuses; pratiques religieuses; représentation du genre. 